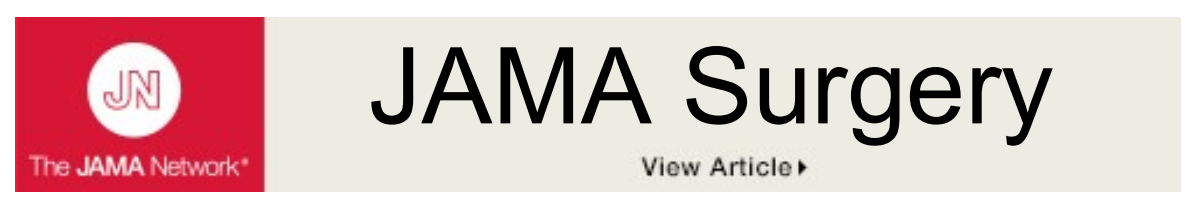

JAMA Surg. 2017 Aug; 152(8): 734-740.

PMCID: PMC5831462

Published online 2017 Apr 5. doi: 10.1001/jamasurg.2017.0461

PMID: 28384780

\title{
Association of Insurance Expansion With Surgical Management of Thyroid Cancer
}

Andrew P. Loehrer, MD, MPH, ${ }^{1}$ Shilpa S. Murthy, MD, MPH ${ }^{2}$ Zirui Song, MD, PhD,${ }^{3}$ Carrie C. Lubitz, MD, MPH, ${ }^{1}$ and Benjamin C. James, MD, MS ${ }^{\bigotimes 2}$

${ }^{1}$ Department of Surgery, Massachusetts General Hospital, Boston

2 Department of Surgery, Indiana University School of Medicine, Indianapolis

3 Department of Medicine, Massachusetts General Hospital, Boston

$\bigotimes_{\text {Corresponding author. }}$

Article Information

Corresponding Author: Benjamin C. James, MD, MS, Section of Endocrine Surgery, Indiana University Division of General Surgery, Indiana University Hospital, 545 Barnhill Dr, EH 537, Indianapolis, IN 46202 (becjames@iupui.edu).

Accepted for Publication: January 27, 2017.

Published Online: April 5, 2017. doi:10.1001/jamasurg.2017.0461

Author Contributions: Dr Loehrer had full access to all of the data in the study and takes responsibility for the integrity of the data and the accuracy of the data analysis.

Study concept and design: James, Loehrer.

Acquisition, analysis, or interpretation of data: All authors.

Drafting of the manuscript: James, Loehrer, Murthy, Lubitz.

Critical revision of the manuscript for important intellectual content: James, Loehrer, Lubitz, Song.

Statistical analysis: Loehrer, Song.

Obtained funding: Song.

Administrative, technical, or material support: James, Loehrer.

Conflict of Interest Disclosures: None reported.

Funding/Support: This study was supported through predoctoral MD/PhD. National Research Service Award 1 F30 AG 03975-ZS from the National Institute on Aging and grant K07CA177900-CCL from the National Institutes of Health-National Cancer Institute.

Role of the Funder/Sponsor: The National Institute on Aging and National Institutes of Health had no role in the design and conduct of the study; collection, management, analysis, and interpretation of the data; and preparation, review, or approval of the manuscript.

Previous Presentation: This study was presented in part at the Annual Meeting of the American Association of Endocrine Surgeons; April 11, 2016; Baltimore, Maryland.

Additional Contributions: We acknowledge the National Bureau of Economic Research, through which data were made available, as well as databases maintained through the Hospital Cost and Utilization Project's data partners, including the Massachusetts Center for Health Information and Analysis, the Florida Agency for Health Care Administration, the New Jersey Department of Health, and the New York State Department of Health.

Received 2016 Jun 21; Accepted 2017 Jan 27.

Copyright 2017 American Medical Association. All Rights Reserved.

Key Points

Go to:

Question

Go to: 
How does insurance expansion affect the rate of thyroidectomy for treating thyroid cancer?

Findings

Go to:

In this study using difference-in-differences models, the 2006 Massachusetts health care reform was associated with a $26 \%$ increased rate of thyroidectomy for treating thyroid cancer and a $21 \%$ increased rate of neck dissection among patients with cancer compared with control states.

Meaning

Go to:

In Massachusetts, the expansion of health care results in an increased treatment of thyroid cancer.

Abstract

Go to:

Importance

Go to:

To our knowledge, thyroid cancer incidence is increasing faster than any other cancer type and is currently the fifth most common cancer among women. While this rise is likely multifactorial, there has been scarce consideration of the effect of insurance statuses on the treatment of thyroid cancer.

\section{Objective}

Go to:

We evaluate the association of insurance expansion with thyroid cancer treatment using the 2006

Massachusetts health reform, which serves as a unique natural experiment.

\section{Design, Setting, and Participants}

Go to:

We used the Agency for Healthcare Research and Quality State Inpatient Databases to identify patients with government-subsidized or self-pay insurance or private insurance who were admitted to a hospital with thyroid cancer and underwent a thyroidectomy between 2001 and 2011 in Massachusetts $(\mathrm{n}=8534)$ and 3 control states $(n=48$ 047). Difference-in-differences models were used to evaluate an association between the 2006 Massachusetts health care reform and thyroid cancer treatment, and participants were controlled for age, sex, comorbidities, and secular trends.

Main Outcomes and Measures

Go to:

Change in the thyroidectomy rate for thyroid cancer treatment was the primary outcome evaluated.

\section{Results}

Go to:

The Massachusetts cohort consisted of 6443 women (75.5\%) and 2091 men (24.5\%), of whom 6388 (79.6\%) were white, 391 (4.9\%) were black, 527 (6.6\%) were Hispanic, 424 (5.3\%) were Asian/Pacific Islander, $63(0.8 \%)$ were Native American, and $228(2.8 \%)$ were other. The participants from control states included 36818 women (76.6\%) and 11229 men (23.4\%), of whom 30432 (65.5\%) were white, 3818 (8.2\%) were black, 6462 (13.9\%) were Hispanic, 2591 (5.6\%) were Asian/Pacific Islander, 211 (0.5\%) were Native American, and 2947 (6.3\%) were other. Before the 2006 Massachusetts insurance expansion, patients with government-subsidized or self-pay insurance had lower thyroidectomy rates for thyroid cancer in Massachusetts and the control states compared with patients with private insurance. The Massachusetts insurance expansion was associated with a $26 \%$ increased rate of undergoing a thyroidectomy (incident rate ratio, 1.26; $95 \% \mathrm{CI}, 1.04-1.52 ; P=.02$ ) and a $22 \%$ increased rate of neck dissection (incident rate ratio, $1.22 ; 95 \% \mathrm{CI}, 1.07-1.37 ; P=.002$ ) for treating cancer compared with control states. 


\section{Conclusions and Relevance}

The 2006 Massachusetts health reform, which is a model for the Affordable Care Act, was associated with a $26 \%$ increased rate of thyroidectomy for treating thyroid cancer. Our study suggests that insurance expansion may be associated with increased access to the surgical management of thyroid cancer. Further studies need to be conducted to evaluate the effect of healthcare expansion at a national level.

The incidence of thyroid cancer has been increasing by $5 \%$ each year over the last decade. By 2019 , it is projected to be the third most common cancer among women younger than 45 years. While there has been an increase in the incidence rate of thyroid cancer, 5-year survival remains above $98 \%$. As life expectancy and the incidence of thyroid cancer rises in the United States, the management and treatment of survivors of thyroid cancer may have a significant economic burden on the US healthcare system. An estimated \$1.6 billion has been cumulatively spent on the treatment of thyroid cancer care since 1985. Forty-one percent of those costs were attributed to diagnosis, surgery, and adjuvant therapy for new thyroid cancer cases and $27 \%$ were attributed to the surveillance of survivors. While the rise in thyroid cancer incidence is likely multifactorial, including the possibility of overdiagnosis, to our knowledge there have been few research studies investigating how insurance expansion influences the diagnosis and treatment of thyroid cancer.

In 2006, Massachusetts passed health care reform legislation that expanded Medicaid, created new subsidized insurance programs for those ineligible for Medicaid, and extended young adult eligibility on parental plans until the age of 26 years. Since then, Massachusetts has seen increased coverage to more than $97 \%$ of residents, with most newly insured people enrolling in either Medicaid or the newly created, subsidized Commonwealth Care insurance (eFigure 1 in the Supplement). Nonwhite residents had particularly striking gains in coverage, with uninsured rates among black and Hispanic residents decreasing from approximately $18 \%$ to fewer than $5 \%$ (eFigure 2 in the Supplement). Previous studies found that this expansion is associated with the increased use of discretionary and acute surgical procedures and increased rates of undergoing resection for other malignancies. The Massachusetts legislation was a framework for the Affordable Care Act, which has provided an estimated 16.9 million Americans insurance coverage. To our knowledge, the effect of insurance expansion on the surgical treatment of thyroid cancer has not been investigated. We evaluated the association of insurance expansion with thyroid cancer treatment using the 2006 Massachusetts health reform, which serves as a unique natural experiment for the potential implications of the Affordable Care Act. We hypothesized that insurance expansion was associated with increased rates of surgical treatment among patients with government-subsidized and self-pay (GSSP) insurance in Massachusetts compared with those in control states. Additionally, we hypothesized that nonwhite patients, who disproportionately gained coverage, had greater increases in undergoing treatment compared with white patients.

Methods Go to:

\section{Study Design and Data}

We identified a cohort of 56581 inpatient admissions using the Hospital Cost and Utilization Project State Inpatient Databases for Massachusetts, New Jersey, New York, and Florida between January 1, 2001, and December 31, 2011. These administrative data are collected and maintained by public-private partnerships that are supported by the Agency of Healthcare Research and Quality. The State Inpatient Databases capture nearly all inpatient discharges in their respective states annually. Control states were selected based on the completeness of the data and a similar availability of primary care and surgical services. We included all nondisabled, nonelderly adult patients with thyroid cancer and all patients who were uninsured or had coverage through Medicaid or Commonwealth Care (available in Massachusetts after 2006). This 
cohort, referred to as GSSP patients, is the primary group that was affected by the reform in Massachusetts or by similar reforms in control states. Sensitivity analyses were performed on privately insured (PI) patients to evaluate for secular trends within Massachusetts. Consistent with previously published studies, admissions of patients with diagnoses of thyroid cancer were determined using the International Classification of Diseases, Ninth Revision, Clinical Modification (ICD-9-CM) diagnosis codes. Patients younger than 18 years and patients who were 65 years or older were excluded from the primary analysis, as the Massachusetts law did not directly affect these populations. Patients with Medicare coverage were also excluded from the analysis, as the 2006 law was not intended to affect Medicare eligibility or benefits. The study was deemed exempt from institutional review board approval because it was a retrospective review using a database that did not have patient-specific data.

\section{Outcomes}

The primary outcome of the study was partial or total thyroidectomy for thyroid cancer treatment. Secondary outcome of interests were neck dissections for thyroid cancer treatment. Thyroidectomy for cancer treatment was defined as if the patient had thyroid cancer and a concurrent procedure code for partial or total thyroidectomy (ICD-9-CM 06.2, 06.31, 06.39, 06.4, 06.50, 06.51, or 06.52). Neck dissection for cancer treatment was defined as if the patient had thyroid cancer and a concurrent procedure code for radical, unilateral, or bilateral neck dissection (ICD-9-CM 40.40, 40.41, or 40.42).

\section{Risk Adjustment}

Multivariable analyses were performed controlling for patient and system-level factors including patient age, sex, race/ethnicity, comorbidities using the Elixhauser Comorbidity Index, hospital type, and secular trends. Race/ethnicity was included as a covariate in analyses examining changes in outcomes for all GSSP patients. To evaluate differential changes by race, cohorts were stratified as being either white or nonwhite (black or Hispanic). Hospital type was classified as either a privately owned hospital with any number of beds or location, not-for-profit rural hospitals with any number of beds, not-for-profit urban hospitals with fewer than 300 beds, and not-for-profit urban hospitals with more than 300 beds. Additional analyses, including hospital-level annual volume of thyroidectomies, did not significantly change our results. For each model we used the Stata-derived cluster-correlated robust estimate of variance to account for clustering within hospitals. We controlled for secular trends using a continuous, quarterly time variable beginning in the first quarter of 2001 and ending with the fourth quarter of 2011.

The primary independent variable of interest was the intervention group (Massachusetts) vs the control group (control states) before and after the 2006 reform. The prereform period was defined as any discharge occurring from the first quarter of 2001 through the second quarter of 2006 when the Massachusetts law was passed. The postreform period was defined as any discharge during or after the first quarter of 2008. We omitted discharges between the third quarter of 2006 and fourth quarter of 2007, as this was a transition period when different elements of the insurance expansion were going into effect. Previous studies suggest that the most significant uptake in insurance coverage occurred after the individual mandate went into effect in January 2008. However, sensitivity analyses including all discharges from 2001 through 2011 did not change our results.

\section{Statistical Analysis}

Our primary analyses used difference-in-differences models to evaluate differential changes in outcomes among GSSP patients in Massachusetts as compared with those in control states. Difference-in-differences models identify changes in outcomes in a group exposed to a policy change compared with an unexposed control group. We used a triple-interaction term between Massachusetts, GSSP, and a postreform variable to evaluate for any differential change in Massachusetts after the implementation of reform compared with 
concurrent trends in control states. This triple-interaction term accounts for not only changes for GSSP in control states but also among PI patients in Massachusetts. The subsequent coefficient represents the independent change in outcomes for GSSP in Massachusetts attributable to the 2006 reform. We used Poisson regression models to evaluate surgical interventions as count data and to estimate the incident rate ratio (IRR) of undergoing thyroidectomy or neck dissections for thyroid cancer. The primary dependent variables in these models were thyroidectomy or neck dissection. The population denominators for GSSP and PI patients were determined using data available through the US Census Bureau. In the final riskadjusted models, the IRR represents the independent effect of the 2006 insurance expansion on thyroidectomy or neck dissection rates among GSSP patients in Massachusetts.

To evaluate changes in thyroidectomy and neck dissections for cancer treatment by the race/ethnicity of patients, we stratified GSSP patients by race/ethnicity and used a 2-way interaction term between Massachusetts and the postreform period. Population denominators were determined using US Census Bureau data. Additional models using a 3-way interaction term between Massachusetts, the postreform period, and nonwhite race/ethnicity did not change our results. Data were analyzed using Stata software, version 14 (StataCorp). All results were considered significant at $P \leq .05$.

Results Go to:

Our cohort included 8534 admissions of patients with thyroid cancer in Massachusetts and 48047 admissions in control states (Table 1). Patients in Massachusetts were similar to those in control states in terms of age, sex, and comorbidities. However, patients in Massachusetts were more likely to be white and less likely to be admitted to private hospitals. Before the reform, there was no differential trend in undergoing a thyroidectomy between Massachusetts and control states among either GSSP (IRR, 1.01; 95\% CI, 0.99-1.03; $P=.18$ ) or PI patients (IRR, 1.00; 95\% CI, 1.00-1.01; $P=.33$ ) (Figure 1). Similarly, there was no differential preexpansion trend in undergoing a neck dissection between Massachusetts and control states among GSSP (IRR, 1.00; 95\% CI, 0.99-1.02; $P=.74$ ) or PI patients (IRR, 1.00; 95\% CI 0.99-1.01; $P$ $=.65$ ) (eFigure 3 in the Supplement).

The Massachusetts coverage expansion was associated with a $26 \%$ increased rate of undergoing a thyroidectomy (IRR, 1.26; 95\% CI, 1.04-1.52; $P=.02$ ) and a $22 \%$ increased rate of undergoing a neck dissection (IRR, 1.22; 95\% CI, 1.07-1.37; $P=.002$ ) among GSSP patients in Massachusetts (Table 2). Sensitivity analyses with patients stratified by payer demonstrated the 2006 insurance expansion was associated with a $27 \%$ increased rate of undergoing a thyroidectomy among GSSP patients in Massachusetts (IRR, 1.27; 95\% CI, 1.05-1.53; $P=.02$ ) but no significant change in thyroidectomy rates among PI patients in Massachusetts (IRR, 1.01; 95\% CI, 0.76-1.34; $P=.97$ ) relative to those in control states. Similarly, stratified analyses for neck dissection insurance expansion was independently associated with a $21 \%$ increased rate of undergoing a neck dissection among GSSP patients in Massachusetts (IRR, $1.21 ; 95 \% \mathrm{CI}, 1.07-1.38 ; P=.003)$ with no change in the rate of undergoing a neck dissection among PI patients in Massachusetts (IRR, $0.97 ; 95 \% \mathrm{CI}, 0.78-1.22 ; P=.81$ ) relative to those in control states. Sensitivity analyses using all discharges during the study period, including the implementation period of 2006 quarter 3 through 2007 quarter 4, did not alter our findings.

Examining these trends further by race/ethnicity, we found that insurance expansion had a particularly strong association with rates of undergoing procedures for nonwhite patients. Before the reform, nonwhite and white patients had comparable rates of undergoing a thyroidectomy in Massachusetts and control states (Figure 2). Stratified analyses found that the 2006 reform was associated with a $68 \%$ increased rate of undergoing a thyroidectomy (IRR $=1.68 ; 95 \% \mathrm{CI}, 1.24-2.29 ; P=.001)$ among nonwhite patients in Massachusetts compared with concurrent trends among patients in control states (Table 3 ). White patients in Massachusetts had an increased rate of undergoing a thyroidectomy that was not statistically significant 
(IRR, 1.22; 95\% CI, 0.98-1.51; $P=.07$ ). Similarly, nonwhite and white patients had similar rates of undergoing a neck dissection in Massachusetts and control states before the reform (eFigure 4 in the Supplement). Analogous to thyroidectomy, the Massachusetts coverage expansion was associated with a $45 \%$ increased rate of undergoing neck dissections (IRR, $1.45 ; 95 \% \mathrm{CI}, 1.12-1.87 ; P=.01$ ) among nonwhite patients compared with control states (Table 3). There was a nonsignificant increase (IRR, 1.16; $95 \%$ CI, 0.99-1.40; $P=.07$ ) in the rate of undergoing a neck dissection for white patients in Massachusetts compared with the trend in control states. Sensitivity analyses using the triple-interaction term between Massachusetts, nonwhite race/ethnicity, and the postreform period confirmed that the expansion was associated with a statistically greater increased rate of undergoing a thyroidectomy (IRR, 1.66; 95\% CI, 1.23-2.24; $P=.001$ ) and neck dissection (IRR, 1.44; 95\% CI, 1.13-1.86; $P=.004$ ) among nonwhite patients in Massachusetts.

\section{Discussion}

Go to:

The incidence of thyroid cancer continues to rise across the country and considerable disparities in diagnosis, management, and outcomes have been documented. Simultaneously, there is growing attention to the potential overdiagnosis and treatments for thyroid cancer. To our knowledge, our study is the first to evaluate the influence of insurance expansion on surgical procedures for thyroid cancer. We found that the Massachusetts insurance expansion was associated with a $26 \%$ increased rate of thyroidectomy and a 22\% increased rate of neck dissections for thyroid cancer. The increased rate occurred disproportionately among nonwhite patients, with a $68 \%$ increased rate of undergoing a thyroidectomy and $45 \%$ increased rate of undergoing neck dissections among nonwhite patients compared with control states.

Although no studies to date to our knowledge have evaluated the effect of health care expansion on the diagnosis and treatment of thyroid cancer, several studies evaluating other medical conditions have suggested that increased insurance coverage is associated with the increased use of services. Early reports on insurance expansion through the Affordable Care Act similarly report an increased use of services among patients after gaining insurance coverage. The findings in this study are consistent with our previous work showing a strong association between the 2006 Massachusetts reform and increased use of surgical services, especially among nonwhite populations.

Our findings suggest that expanded insurance coverage has contributed to increased diagnoses and interventions on thyroid cancer, most likely because of an increased access to care. Patients may be presenting more readily to primary care clinicians and may be referred at a higher rate to specialists who are more likely to intervene. While there are certainly benefits to expanding health insurance coverage, including the diagnosis and treatment of cancer, there must also be thoughtful consideration to the appropriateness of diagnostic and treatment modalities.

Increasing attention is being directed toward the most efficient and effective methods of managing thyroid cancer. Previous reports suggest that the overdiagnosis of small, papillary thyroid carcinoma accounts for a significant portion of the rising incidence of thyroid cancer. However, the increased incident rate of these small cancers predates this study and is unlikely to have influenced our findings selectively for GSSP patients in Massachusetts. The data used in this study do not provide adequate oncologic granularity to determine pathologic diagnoses, stages of disease, or long-term outcomes. Therefore, it remains unclear whether increased intervention, as seen after the insurance expansion in Massachusetts, will necessarily translate into improved morbidity and prognosis.

The present study was not designed to explicitly examine the appropriateness of thyroidectomy for cancer. Despite a disproportionate increase in thyroidectomy for cancer after insurance expansion, GSSP patients in Massachusetts still had lower resection rates than privately insured patients in the state (eFigure 5 in the Supplement). However, we cannot determine whether this gap in thyroidectomy rates represents a 
persistent disparity in care for GSSP patients, an overuse of surgery among PI patients, or some combination of the two. The increased rates in Massachusetts, however, provide important insights into potential changes to insurance expansion elsewhere in the country.

\section{Limitations}

We acknowledge several important limitations. First, the State Inpatient Databases are composed of administrative data that are susceptible to coding errors. However, Healthcare Cost and Utilization Project data have been used extensively in prior studies evaluating thyroid cancer. Furthermore, it is unlikely that coding discrepancies would selectively and directionally lead to increased rates of thyroidectomy and neck dissections among GSSP patients in Massachusetts without concordant changes among PI patients. Using the State Inpatient Databases, we are unfortunately unable to identify the specific individuals that gained insurance after the Massachusetts reform. We included a much broader population of individuals who were potentially affected by insurance expansion before and after the reform in both Massachusetts and control states. Consequently, we included many individuals in Massachusetts that were covered by Medicaid before and after the reform. However, including these patients would dilute the measured effect of insurance expansion rather than amplify findings.

Our analysis is also limited in capturing only inpatient surgical procedures. In recent years, more thyroidectomies are performed in the outpatient setting. After examining data from the New York State Ambulatory Surgery Database and State Inpatient Database, it was recently reported that approximately $17 \%$ of thyroidectomies were done in an ambulatory setting, although more than $90 \%$ of all Medicaid patients had the procedure in an inpatient setting. Unfortunately, there is no Ambulatory Surgery Database available in Massachusetts and we are unable to comment on outpatient procedures before and after the 2006 expansion.

Finally, Massachusetts was a unique health care environment even before the 2006 reform, with small uninsured populations and a high concentration of health care professionals. Thus, the Massachusetts experience may not be generalizable elsewhere in the country. An evaluation of parallel trends before the reform reveals similar rates and trends between Massachusetts and control states before the expansion. Other factors independent of insurance expansion, such as changes in the number of trained or practicing endocrine surgeons in Massachusetts, could also have influenced rates after the reform. However, our evaluation of trends among PI patients in Massachusetts, who were less directly affected by the 2006 reform, showed no significant change in outcomes after implementation. Collectively, these findings argue against alternative factors between states or within Massachusetts driving the increased receipt of thyroidectomy and neck dissections for thyroid cancer among GSSP patients after insurance expansion. Nonetheless, given the unique aspects of Massachusetts, the control states used in this study may not fully represent the counterfactual of Massachusetts without reform. While we are unable to fully overcome these limitations with the data available, ongoing evaluation of states expanding insurance coverage through the Affordable Care Act will provide much greater insights. As 19 remaining states consider whether to expand Medicaid as a part of the Affordable Care Act, our findings provide important information about how such an expansion may influence care delivery for thyroid cancer. Policy makers, researchers, and health systems should continue to critically analyze the effects of ongoing policy changes on the accessibility and equity of clinical care.

In this study, we report that the 2006 Massachusetts insurance expansion was associated with significant increases in surgical intervention for thyroid cancer, specifically among nonwhite populations. Our findings provide encouraging evidence that insurance coverage may help mitigate racial or socioeconomic disparities while also raising questions concerning the relative appropriateness of the observed management 
of thyroid cancer, which deserves additional investigation.

Notes

Go to:

Supplement.

eFigure 1. Trends in Insurance Coverage in Masschusetts.

eFigure 2. Trends in the Percentage of Massachusetts Population That Was Uninsured, by

Race/Ethnicity.

eFigure 3. Unadjusted Trends in Neck Dissection for Thyroid Cancer in Government Subsidized/Self-pay Patients in Massachusetts and Control States.

eFigure 4. Unadjusted Trends in Neck Dissection for Cancer in Government Subsidized/Self-pay Patients in Massachusetts and Control States, by Patient Race/Ethnicity.

eFigure 5. Unadjusted Trends in Thyroidectomy for Cancer in Massachusetts and Control States, by Payer

References

Go to:

1. Davies L, Welch HG. Increasing incidence of thyroid cancer in the United States, 1973-2002. JAMA. 2006;295(18):2164-2167. [PubMed: 16684987]

2. National Cancer Institute Surveillance, Epidemiology, and End Results Program SEER stat fact sheets: thyroid cancer. http://seer.cancer.gov/statfacts/html/thyro.html. Accessed May 1, 2015.

3. Chen AY, Jemal A, Ward EM. Increasing incidence of differentiated thyroid cancer in the United States, 1988-2005. Cancer. 2009;115(16):3801-3807. [PubMed: 19598221]

4. Arias E. United States life tables, 2009. Natl Vital Stat Rep. 2014;62(7):1-63. [PubMed: 24393483]

5. Lubitz CC, Kong CY, McMahon PM, et al. Annual financial impact of well-differentiated thyroid cancer care in the United States. Cancer. 2014;120(9):1345-1352. [PMCID: PMC3999178] [PubMed: 24481684]

6. The General Court of Massachusetts An act providing access to affordable, quality, accountable health care. https://malegislature.gov/Laws/SessionLaws/Acts/2006/Chapter58. Accessed May 1, 2015.

7. Massachusetts Division of Health Care Finance and Policy Massachusetts household survey on health insurance status, 2007. http://archives.lib.state.ma.us/bitstream/handle/2452/58018 locn690284055.pdf?sequence=1. Accessed May 16, 2016

8. Massachusetts Division of Health Care Finance and Policy Massachusetts health insurance survey. http://www.chiamass.gov/massachusetts-health-insurance-survey. Accessed May 16, 2016.

9. Ellimoottil C, Miller S, Ayanian JZ, Miller DC. Effect of insurance expansion on utilization of inpatient surgery. JAMA Surg. 2014;149(8):829-836. [PMCID: PMC4209916] [PubMed: 24988945]

10. Loehrer AP, Chang DC, Hutter MM, et al. Health insurance expansion and treatment of pancreatic cancer: does increased access lead to improved care? J Am Coll Surg. 2015;221(6):1015-1022.

[PMCID: PMC4662773] [PubMed: 26611798]

11. Loehrer AP, Hawkins AT, Auchincloss HG, Song Z, Hutter MM, Patel VI. Impact of expanded insurance coverage on racial disparities in vascular disease: insights from Massachusetts. Ann Surg. 
2016;263(4):705-711. [PMCID: PMC4777641] [PubMed: 26587850]

12. Loehrer AP, Song Z, Auchincloss HG, Hutter MM. Massachusetts health care reform and reduced racial disparities in minimally invasive surgery. JAMA Surg. 2013;148(12):1116-1122. [PMCID: PMC3991927] [PubMed: 24089326]

13. Loehrer AP, Song Z, Auchincloss HG, Hutter MM. Influence of health insurance expansion on disparities in the treatment of acute cholecystitis. Ann Surg. 2015;262(1):139-145.

[PMCID: PMC4464963] [PubMed: 25775059]

14. Carman KG, Eibner C, Paddock SM. Trends in health insurance enrollment, 2013-15. Health Aff (Millwood). 2015;34(6):1044-1048. [PubMed: 25947173]

15. Darthmouth Atlas of Health Care Understanding of the efficiency and effectiveness of the health care system. http://www.dartmouthatlas.org/. Accessed May 1, 2015.

16. Noureldine SI, Abbas A, Tufano RP, et al. The impact of surgical volume on racial disparity in thyroid and parathyroid surgery. Ann Surg Oncol. 2014;21(8):2733-2739. [PubMed: 24633666]

17. Elixhauser A, Steiner C, Harris DR, Coffey RM. Comorbidity measures for use with administrative data. Med Care. 1998;36(1):8-27. [PubMed: 9431328]

18. Rogers WH. Regression standard errors in clustered samples. Stata Tech Bull. 1993;13:19-23. http://www.stata.com/products/stb/journals/stb13.pdf.

19. Chandra A, Gruber J, McKnight R. The importance of the individual mandate-evidence from Massachusetts. N Engl J Med. 2011;364(4):293-295. [PubMed: 21226568]

20. Donald SG, Lang K. Inference with difference-in-differences and other panel data. Rev Econ Stat. 2007;89(2):221-233. dx.doi/10.1162/rest.89.2.221

21. Wooldridge JM. Econometric Analysis of Cross Section and Panel Data. Cambridge, MA: MIT Press; 2002.

22. Arthey S, Imbens GW. Identification and inference in nonlinear difference-in-differences models. Econometrica. 2006;74(2):431-497. dx.doi.org/10.1111/j.1468-0262.2006.00668.x

23. US Census Bureau Historic tables. http://www.census.gov/hhes/www/hlthins/data/historical /HIB tables.html. Accessed May 1, 2015.

24. Baicker K, Taubman SL, Allen HL, et al. ; Oregon Health Study Group . The Oregon experimenteffects of Medicaid on clinical outcomes. N Engl J Med. 2013;368(18):1713-1722.

[PMCID: PMC3701298] [PubMed: 23635051]

25. Pande AH, Ross-Degnan D, Zaslavsky AM, Salomon JA. Effects of healthcare reforms on coverage, access, and disparities: quasi-experimental analysis of evidence from Massachusetts. Am J Prev Med. 2011;41(1):1-8. [PubMed: 21665057]

26. Freeman JD, Kadiyala S, Bell JF, Martin DP. The causal effect of health insurance on utilization and outcomes in adults: a systematic review of US studies. Med Care. 2008;46(10):1023-1032.

[PubMed: 18815523]

27. Sommers BD, Gunja MZ, Finegold K, Musco T. Changes in self-reported insurance coverage, access to care, and health under the Affordable Care Act. JAMA. 2015;314(4):366-374. [PubMed: 26219054]

28. Nikiforov YE, Seethala RR, Tallini G, et al. Nomenclature revision for encapsulated follicular variant of papillary thyroid carcinoma: a paradigm shift to reduce overtreatment of indolent tumors. JAMA Oncol. 
2016;2(8):1023-1029. [PMCID: PMC5539411] [PubMed: 27078145]

29. Vaccarella S, Franceschi S, Bray F, Wild CP, Plummer M, Dal Maso L. Worldwide thyroid-cancer epidemic? the increasing impact of overdiagnosis. N Engl J Med. 2016;375(7):614-617.

[PubMed: 27532827]

30. Sosa JA, Mehta PJ, Wang TS, Yeo HL, Roman SA. Racial disparities in clinical and economic outcomes from thyroidectomy. Ann Surg. 2007;246(6):1083-1091. [PubMed: 18043114]

31. Al-Qurayshi Z, Mohamed H, Bhatia P, Srivastav S, Aslam R, Kandil E. Comparison of secondary and primary thyroid cancer: patient characteristics and postoperative outcomes: a cross-sectional analysis of patients with primary and secondary thyroid cancers. Ann Surg Oncol. 2015;22(suppl 3):S691-S698. [PubMed: 26282905]

32. Kandil E, Noureldine SI, Abbas A, Tufano RP. The impact of surgical volume on patient outcomes following thyroid surgery. Surgery. 2013;154(6):1346-1352. [PubMed: 24238052]

33. Sun GH, DeMonner S, Davis MM. Epidemiological and economic trends in inpatient and outpatient thyroidectomy in the United States, 1996-2006. Thyroid. 2013;23(6):727-733. [PubMed: 23173840]

34. Tuggle CT, Roman S, Udelsman R, Sosa JA. Same-day thyroidectomy: a review of practice patterns and outcomes for 1,168 procedures in New York state. Ann Surg Oncol. 2011;18(4):1035-1040.

[PubMed: 21086054]

Figures and Tables

Go to: 


\section{Table 1.}

\section{Demographic and Clinical Characteristics}

\begin{tabular}{|c|c|c|}
\hline \multicolumn{3}{|c|}{ Demographic and Clinical Characteristics } \\
\hline Characteristic & Massachusetts & Control States \\
\hline Thyroid cancer, No. & 8534 & 48047 \\
\hline Thyroidectomy, No. (\%) & $6627(77.8)$ & $30349(63.2)$ \\
\hline Age, mean (SD) & $44.5(11.4)$ & $44.8(11.4)$ \\
\hline Women, No. (\%) & $6443(75.5)$ & $36818(76.6)$ \\
\hline \multicolumn{3}{|l|}{ Race/ethnicity, No. (\%) } \\
\hline White & $6388(79.6)$ & $30432(65.5)$ \\
\hline Black & $391(4.9)$ & $3818(8.2)$ \\
\hline Hispanic & $527(6.6)$ & $6462(13.9)$ \\
\hline Asian/Pacific Islander & $424(5.3)$ & $2591(5.6)$ \\
\hline Native American & $63(0.8)$ & $211(0.5)$ \\
\hline Other & $228(2.8)$ & $2947(6.3)$ \\
\hline Elixhauser Comorbidity Index, mean (SD) & $0.9(1.1)$ & $0.9(1.1)$ \\
\hline Private insurance coverage, No. (\%) & $7332(88.2)$ & $39444(82.1)$ \\
\hline \multicolumn{3}{|l|}{ Hospital type, No. (\%) } \\
\hline Private & $147(1.7)$ & $2845(5.9)$ \\
\hline \multicolumn{3}{|l|}{ NFP } \\
\hline Rural & $65(0.8)$ & $399(0.8)$ \\
\hline Urban, $<300$ beds & $1943(22.8)$ & 8544 (17.8) \\
\hline Urban, $>300$ beds & $6377(74.7)$ & $36222(75.5)$ \\
\hline
\end{tabular}

Abbreviation: NFP, not-for-profit.

Penter


Association of Insurance Expansion With Surgical Management of Thyro... https://www.ncbi.nlm.nih.gov/pmc/articles/PMC5831462/?report=printable

Figure 1.

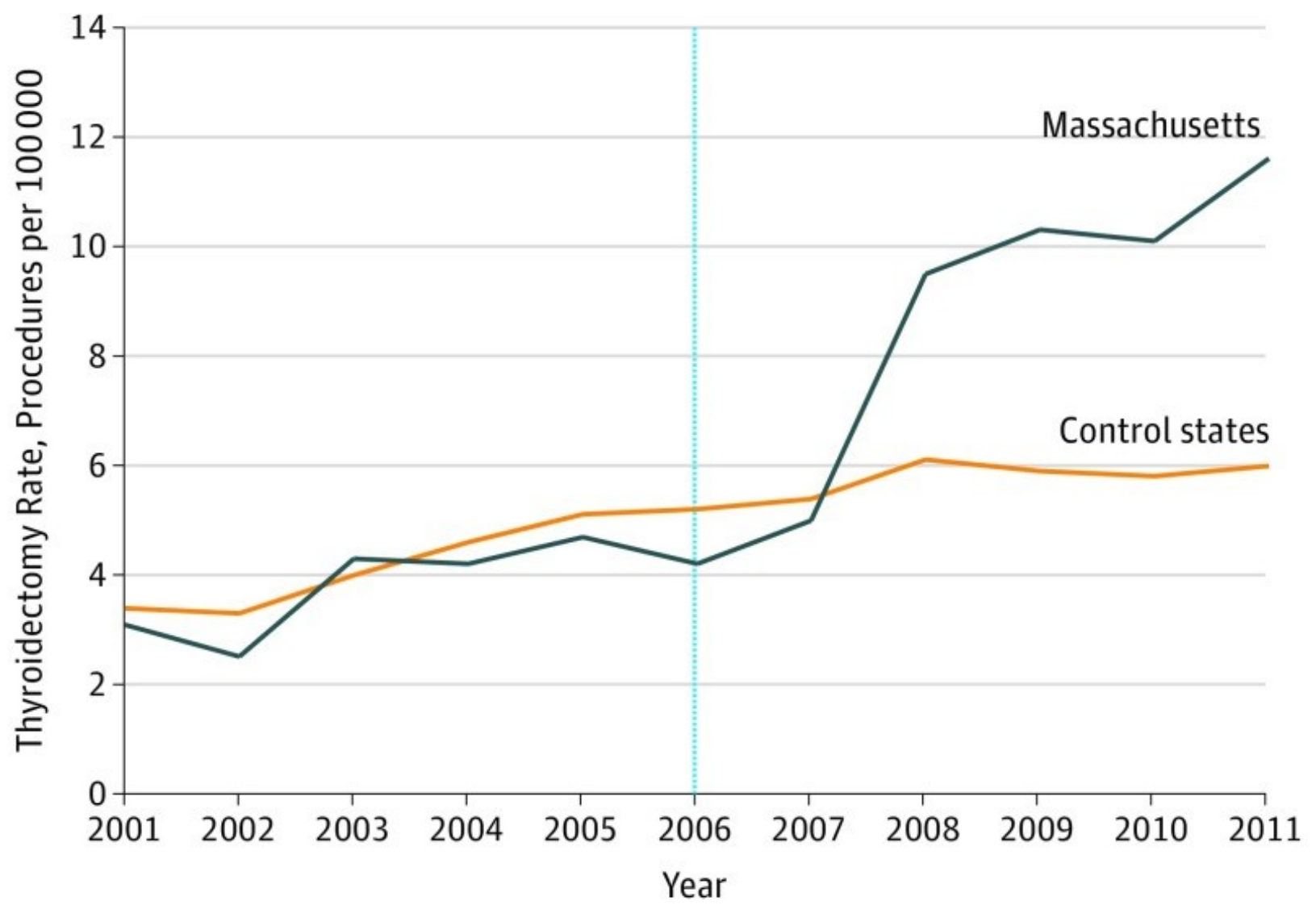

Unadjusted Trends in Undergoing Thyroidectomy for Cancer Among Government-Subsidized/Self-pay Patients in Massachusetts and Control States

The vertical line indicates the year of the Massachusetts health care reform. 


\section{Table 2. \\ Effect of the Insurance Expansion in Massachusetts on Rates of Undergoing Thyroidectomy
and Neck Dissection for Cancer Among Government-Subsidized/Self-pay Patients \\ Effect of the Insurance Expansion in Massachusetts on Rates of Undergoing Thyroidectomy
and Neck Dissection for Cancer Among Government-Subsidized/Self-pay Patients}

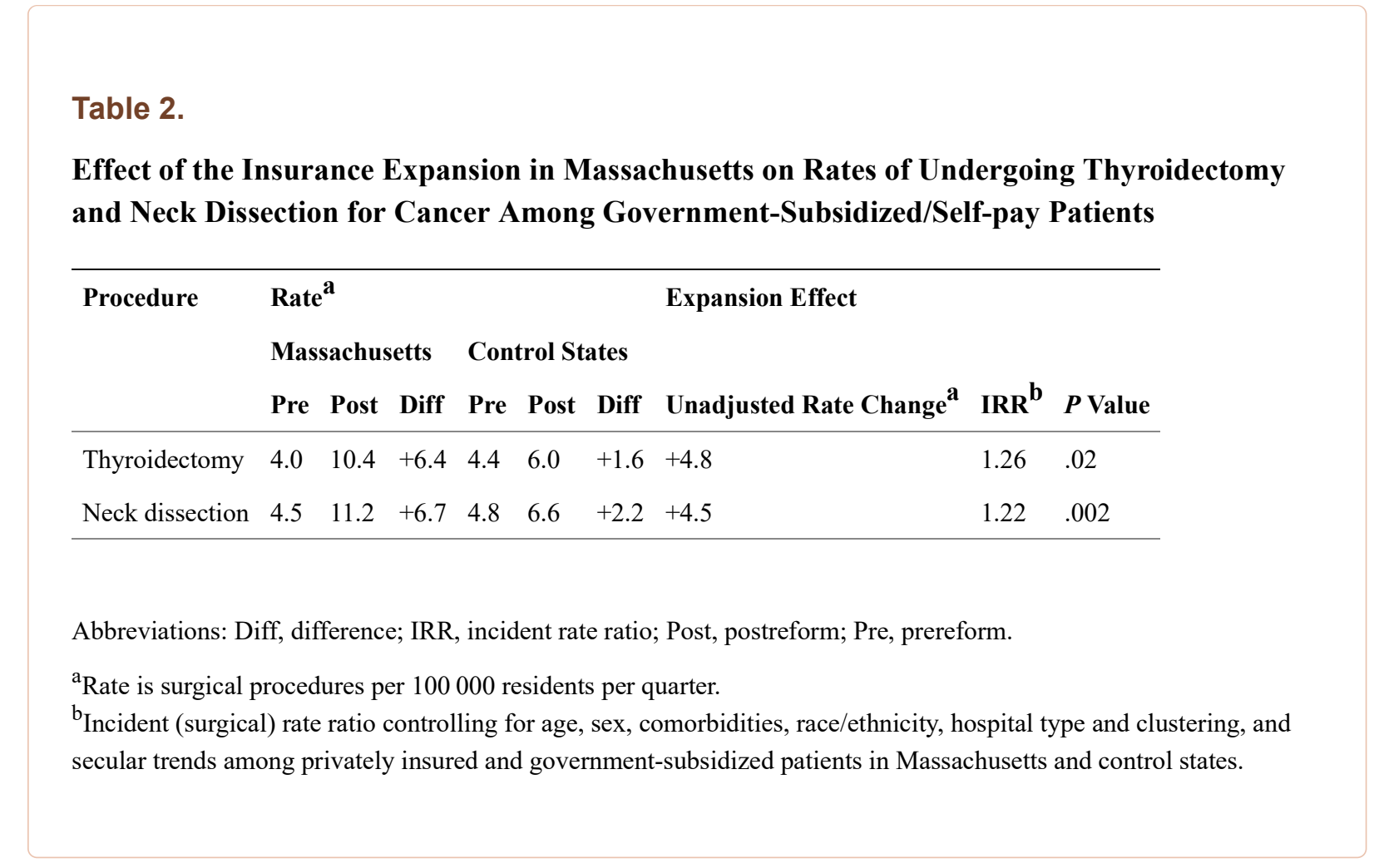

Abbreviations: Diff, difference; IRR, incident rate ratio; Post, postreform; Pre, prereform.

${ }^{\mathrm{a}}$ Rate is surgical procedures per 100000 residents per quarter.

${ }^{\mathrm{b}}$ Incident (surgical) rate ratio controlling for age, sex, comorbidities, race/ethnicity, hospital type and clustering, and secular trends among privately insured and government-subsidized patients in Massachusetts and control states. secular trends anong privately insured and government-subsidized patients in Massachusetts and control states. (a)

. https://www.ncbi.nlm.nih.gov/pmc/articles/PMC5831462/?report=printable 
Figure 2.

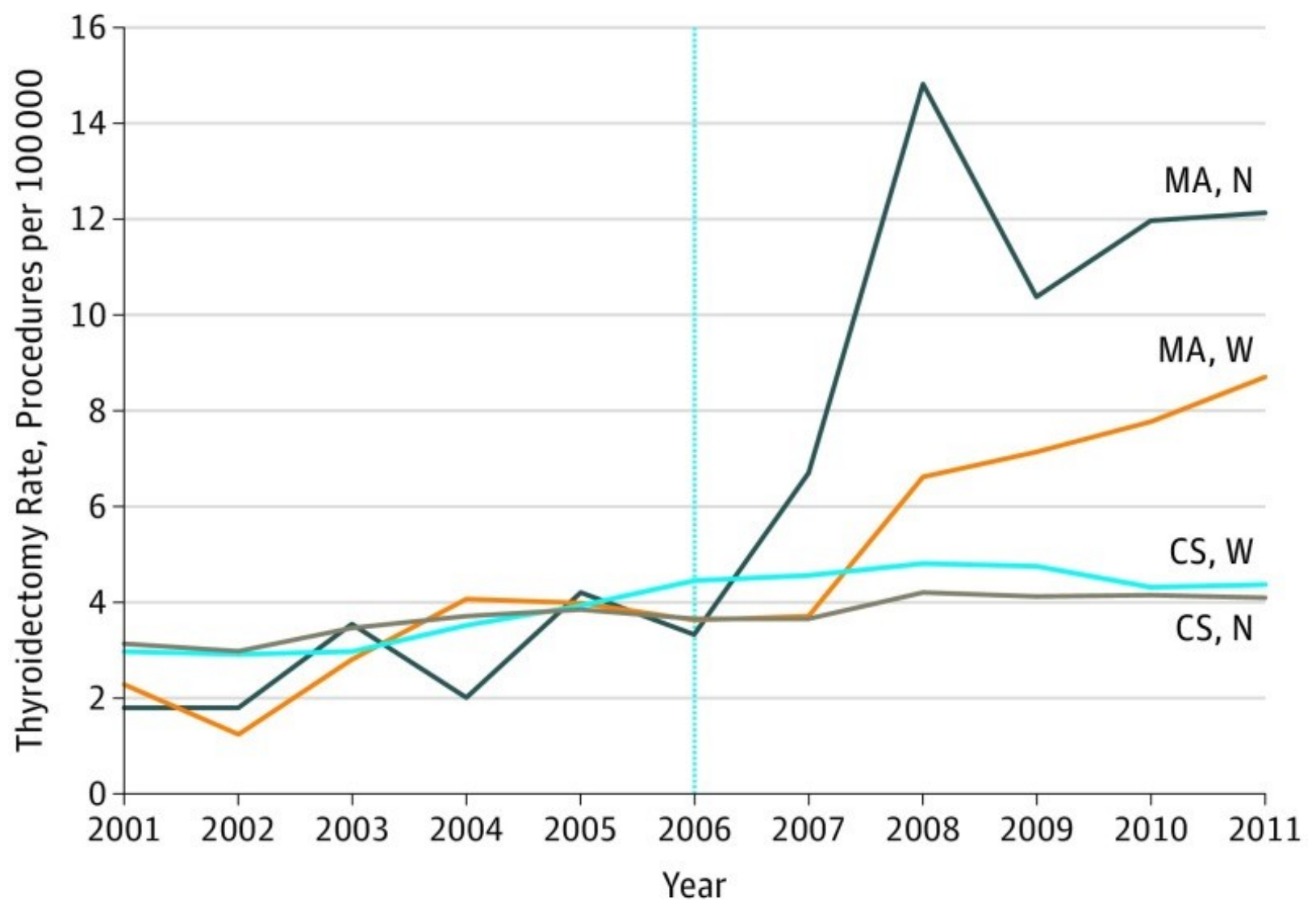

Unadjusted Trends in Undergoing Thyroidectomy for Cancer Among Government-Subsidized/Self-pay Patients in Massachusetts and Control States, by Patient Race/Ethnicity

The vertical line indicates the year of the Massachusetts health care reform. MA, N indicates Massachusetts, nonwhite patients; MA, W indicates Massachusetts, white patients; CS, W indicates control states, white patients; and CS, N indicates control states, nonwhite patients. 
Table 3.

Effect of the Massachusetts Insurance Expansion on Rates of Undergoing Thyroidectomy and Neck Dissection for Cancer by Patient Race/Ethnicity

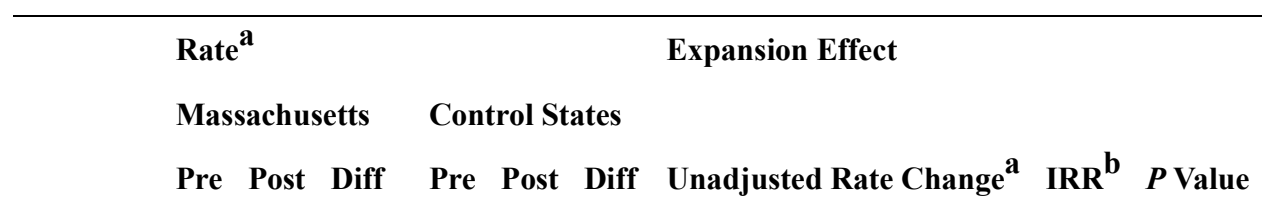

\section{Thyroidectomy}

White

$3.4 \quad 7.7$

$\begin{array}{lllll}+4.3 & 3.5 & 4.6 & +1.1 & +3.2\end{array}$

$\begin{array}{ll}1.22 & .07\end{array}$

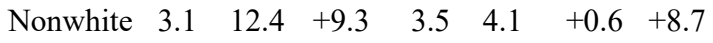

$1.68 \quad .001$

Neck Dissection

White

\begin{tabular}{llllll}
4.0 & 8.2 & +4.2 & 3.9 & 5.1 & +1.2 \\
\hline & +3.0
\end{tabular}

$1.16 \quad .07$

$\begin{array}{llllllll}\text { Nonwhite } & 3.3 & 13.7 & +10.4 & 3.9 & 4.7 & +0.8 & +9.6\end{array}$

$1.45 \quad .01$

Abbreviations: Diff, difference; IRR, incident rate ratio; Post, postreform; Pre, prereform.

${ }^{\mathrm{a}}$ Rate is surgical procedures per 100000 residents per quarter.

${ }^{\mathrm{b}}$ Incident (surgical) Rate Ratio controlling for age, sex, comorbidities, race, hospital type and clustering, and secular trends for government-subsidized patients in Massachusetts and control states. 